\title{
Vitrectomy in high myopia: a narrative review
}

\author{
Michele Coppola ${ }^{1}$, Alessandro Rabiolo ${ }^{2}$, Maria Vittoria Cicinelli ${ }^{2}$, Giuseppe Querques ${ }^{2 *}$ and Francesco Bandello ${ }^{2}$
}

\begin{abstract}
Pathologic myopia is associated with degenerative changes of the globe, especially at the posterior pole. Eyes affected by pathologic myopia have higher odds to undergo posterior segment surgery and, in those eyes, vitreoretinal surgery is challenging. Many practical tips and tricks can make the surgical procedures simpler, significantly preventing sight-threatening intra- and post-operative complications. Moreover, novel surgical techniques and technological advancements (i.e. ad-hoc instrumentation, minimally invasive vitreoretinal surgery, filters, dye staining, intraoperative optical coherence tomography and 3-dimensional surgery) may play role in highly myopic eyes. The aim of the present work is to review practical tips and tricks, novel surgical techniques and technological advancements.
\end{abstract}

Keywords: Degenerative myopia, Epiretinal membrane, Intraoperative optical coherence tomography, Inner limiting membrane, Inverted flap, Macular hole, Pathologic myopia, Posterior staphyloma, Pars plana vitrectomy, Three-

dimensional surgery

\section{Background}

Pathologic (or degenerative) myopia is defined as a refractive error $>6$ diopters (D) and/or axial length $>26.5 \mathrm{~mm}$ associated with degenerative changes of the eyeball, especially at posterior pole [1]. It has an estimated prevalence of $1-2 \%$ in the United States, but it can be even tenfold higher in some districts of Asia and the Middle East [2]. During the past 50-60 years, the prevalence of myopia has been dramatically increasing and some evidence suggest that this trend will worsen with the socio-economic growth of underdevelopment countries [3]. Eyes with high myopia have higher odds of undergoing vitreoretinal surgery due to affections peculiar of myopia (e.g. foveoschisis) or to retinal pathologies (e.g. macular hole $[\mathrm{MH}]$, epiretinal membrane [ERM], rhegmatogenous retinal detachment [RD], and vitreous floaters) nonspecific of myopia, but that occur earlier, more frequently or more severely in myopic eyes [1]. Vitreoretinal surgeon's skills play a primary role in the

\footnotetext{
*Correspondence: giuseppe.querques@hotmail.it

${ }^{2}$ Department of Ophthalmology, University Vita-Salute, IRCCS Ospedale

San Raffaele, Via Olgettina 60, 20132 Milan, Italy

Full list of author information is available at the end of the article
}

management of these complications; however, surgery in such eyes is challenging due to higher axial length, posterior staphyloma, thinner and atrophic retina, degenerated vitreous, thinner sclera and abnormal scleral fibers architecture [4].

The aim of this review is to provide practical tips and tricks for vitrectomy in eyes with pathological myopia. Moreover, novel surgical techniques and technological advancements (i.e. ad-hoc instrumentation, minimally invasive vitreoretinal surgery, filters, dye staining, intraoperative optical coherence tomography (iOCT) and 3-dimensional (3D) surgery) will be presented in this narrative review. Table 1 summarizes most of the traditional and novel techiniques to deal with common and challenging issues that the surgeon has to deal with when operating highly myopic eyes.

\section{Axial length}

Due to increased axial length and posterior staphyloma, standard instruments may be too short, and therefore unable to reach the retinal surface, especially at the posterior pole [5]. As a consequence, some maneuvers (e.g. fluid or perfluorocarbon liquid removal, ERM and inner limiting membrane [ILM] peeling) may be severely 


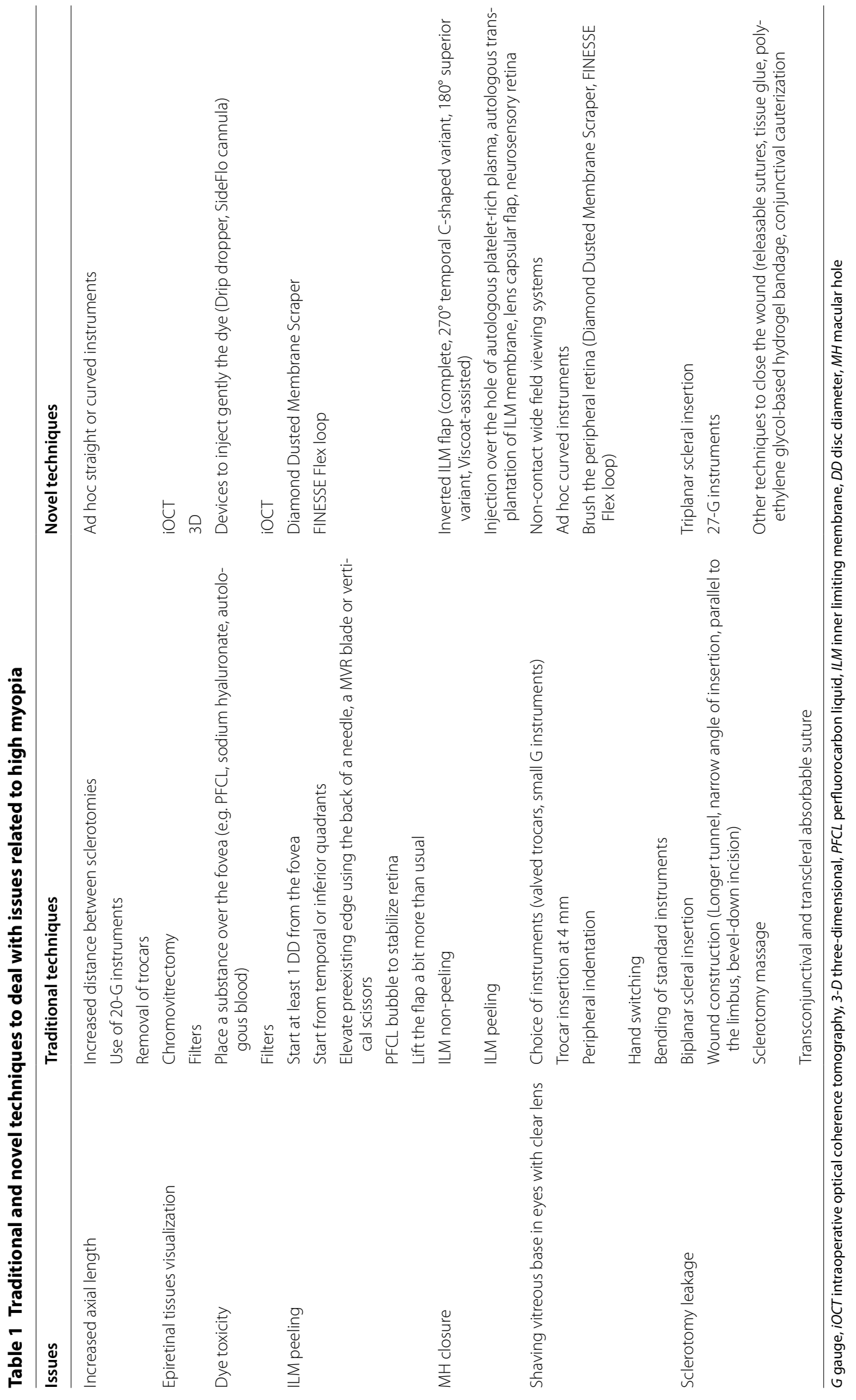


impaired [5]. The surgeon has to verticalize the instruments and apply pressure on the sclera in order to transitorily shorten the axial length of the eyeball $[4,6]$. All these elements result in reduced surgeon's maneuverability, erroneous contact with the viewing system, limited visibility because of corneal folds, longer and more challenging surgical procedures $[4,6]$. Some practical tips can be employed to overcome these issues. First, patients with high myopia should undergo axial length measurement and B-scan ultrasonography to identify eventual posterior staphyloma, to adequately plan the intraoperative approach [5]. In order to avoid instruments verticalization and to restore an adequate working angle, the distance between sclerotomies should be increased [6]. Contrary to 25- and 27-gauge (G) devices, 20-G instruments are longer enough to reach the posterior pole, and temporal sclerotomy can be enlarged in order to accommodate such instruments [5]. Alternatively, trocars can be removed during the surgery and the 25-G/27-G microcannula can be directly inserted into the vitreous cavity to gain extra millimeters. Recently, dedicated instrumentation has been developed to deal with longer eyes, such as long-shaft forceps and long cannulae, chosen on the basis of axial length [7]. In order to avoid conflict with the viewing system, curved elongated instruments can be used instead of straight elongated ones [6].

\section{Epiretinal membrane and inner limiting membrane visualization}

ERM and ILM visualization, mobilization, and removal are more challenging in highly myopic than in emmetropic eyes, due to thinner and atrophic retina, more friable tissues, and longer axial length (for the reasons explained above). All these factors may result in incomplete ERM/ILM removal and paracentral iatrogenic macular holes $[8,9]$. ILM peeling is a delicate maneuver and some precautions should be adopted to avoid complications. Peeling initiation is the most difficult and dangerous step. Since paracentral iatrogenic macular holes impair visual function only if close to the fovea, ILM peeling should be initiated at least 1-disc diameter away from the fovea [9]. Moreover, ILM dissection should begin at the inferior or temporal quadrants avoiding the superior and nasal quadrants because it can limit the view of the surgical field due to the instrument itself or it can damage papillomacular bundle, respectively. Although many surgeons initiate the dissection using the forceps searching for a natural edge of the ILM, it is advisable to enlarge and elevate a preexisting one or create a new edge in case of absence. On this regard, several instruments commonly found in the in the vitreoretinal surgeon's armamentarium may be used including the back of a needle, a microvitreoretinal blade or the lower blade of a vertical scissor [10]. These instruments, however, may traumatize outer retinal layers and novel dedicated tools have been proposed to gain an edge, such as the Diamond Dusted Membrane Scraper (Synergetics) $[10,11]$ and the FINESSE Flex loop (Alcon, Fort Worth, TX, USA) [12]. It has been demonstrated using iOCT the occurrence of micro- and macro-architectural abnormalities during the surgery, which are more pronounced using a direct pinch-and-peel technique, than using the Diamond Dusted Membrane Scraper, which is, in turn, more traumatic than the FINESSE Flex loop [12, 13]. Since myopic ILM and retinal tissues are more fragile, a bubble of perfluorocarbon liquid may be placed on the macular area to stabilize the retina [14]. When performing the peeling, the flap should be lifted a little bit more than usual in order to avoid contact with the wall of the staphyloma.

Several procedures can be adopted to improve visualization and obtain complete removal of ERM and ILM, with minor trauma to the retinal tissue, including chromovitrectomy, filters, iOCT and 3D system.

Chromovitrectomy refers to the use of dyes to stain preretinal tissue and membranes during vitrectomy [15]. Common dyes stain the vitreous (i.e. triamcinolone acetonide, sodium fluorescein and lutein/zeaxanthin), the ERM (i.e. trypan blue, patent blue) and the ILM (indocyanine green [ICG], infracyanine green, brilliant blue, lutein/zeaxanthin + brilliant blue) [15]. Introduced for the first time in 2000, ICG allows a better removal of ILM and better outcomes even in highly myopic eyes, by increasing ILM visualization and stiffness, avoiding its fragmentation and multiple grasping [16]. However, ICG exerts a toxic effect on the retina, especially towards the outer layers and the retinal pigment epithelium, and therefore, nowadays, less harmful vital dyes are preferred [15]. Staining the vitreous is very useful in these patients since many cases of apparent complete posterior detachment have the vitreous cortex attached to the retina, especially in foveoschisis and $\mathrm{MH}$ [17]. Due to the vitreoschisis and adherent vitreous cortex on retinal surface, tractional tissues in those eyes are multilayered and heterogeneous consisting of vitreous cortex residuals, ERM and ILM [18]. The surgeon must pay attention to delaminate all the components and chromovitrectomy is extremely useful in this setting. Tissue-specific dyes are of great importance to selectively stain and properly identify the residual vitreous cortex, the ERM and the ILM [19]. Since myopic ILM is firmly adherent, friable and sticky, multiple stainings are advisable to be sure of its complete removal [20].

According to the previous literature, the potential toxic effect of vital dyes arises from the contact between retinal 
pigment epithelium and the dye itself [21]. Therefore, several substances have been employed in order to create a protective layer over the retina during macular hole surgery, to prevent migration of the dyes into the subretinal space, including sodium hyaluronate [22], perfluorocarbon liquid [23] and autologous blood [24]. In addition, many devices (e.g. drip dropper, or SideFlo cannula) have been proposed to inject the dye gently into the vitreous cavity, avoiding fluidic turbulence with dye migration into the subretinal space $[25,26]$.

Along with the type of dye, also light filters may improve visualization of stained ILM by improving tissue contrast. Amber filters aid the removal of ILM stained with brilliant blue, whereas a green filter is preferred when ILM is colored with other dyes [27]. These filters have shown to reduce retinal light toxicity [28].

Microscope-integrated iOCT is an emergent, fascinating technology, which allows the real-time visualization of tissue-instruments interactions. In the setting of macular surgery, iOCT may permit the identification of residual ERM/ILM that would otherwise not have been identified by commercially available microscopes and may guide the surgeon in the intraoperative decision making (Fig. 1) [29].

3D surgery is a newborn technology in which the image is displayed in a large flat monitor letting the surgeon perform different procedures in a heads-up position wearing polarized eyeglasses [30]. Although few papers have been published so far, compared to standard microscope, this technology appears extremely attracting in myopic eyes since it displays images in high definition, and allows good visualization of the vitreous and other tissues using specific channels (e.g. green for vitreous) and modifying image parameters, as digital gain, contrast, and brightness (personal communication, presented at FLOREtina 2017).

Although most of the above-mentioned considerations may be beneficial also in emmetropic eyes, they become extremely precious in pathologic myopia.

The extension of peeling of the ILM membrane in eyes with myopic macular disease is a matter of controversy. On one hand, smaller ILM peeling is more respectful toward retinal nerve fiber layer [31,32]. On the other hand, ILM is probably the most rigid and non-compliant structure in myopic retina and a wider peeling till to the retinal arcades may allow the relaxation of the elastic retinal tissue [33-36]. Although a complete and wide ILM peeling is beneficial in some kind of myopic macular disease (i.e. $\mathrm{MH}$, foveoschisis-associated $\mathrm{MH}$ ), it can be harmful in others, including myopic foveoschisis, where an iatrogenic $\mathrm{MH}$ may occur due to breakage in the thin central perifoveal tissue [37]. To prevent this complication, it is possible to adopt a center-sparing technique leaving a circular intact ILM fragment around the

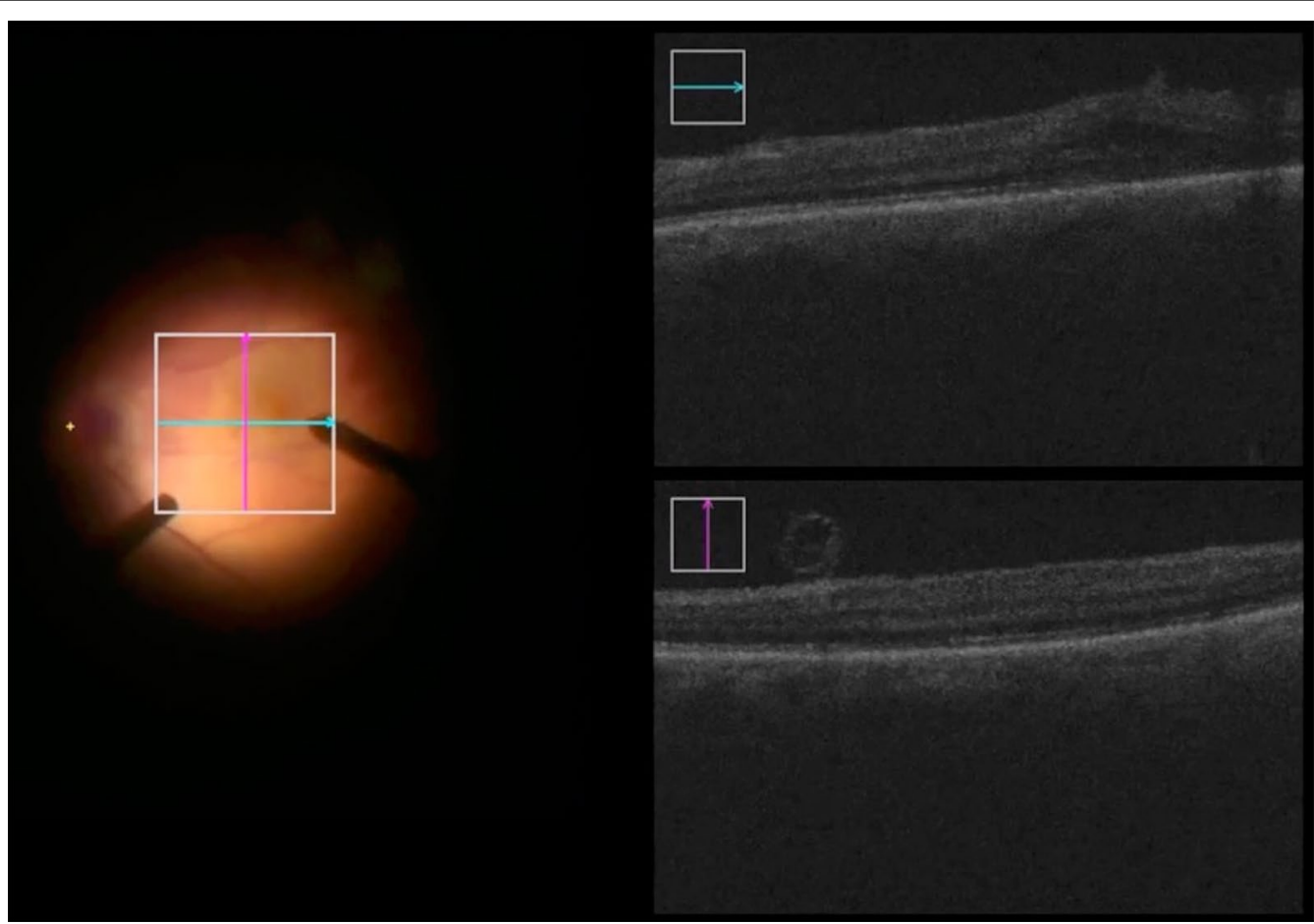

Fig. 1 Intraoperative optical coherence tomography assisted inner limiting membrane removal 
fovea in order to release the tangential tractions with no mechanical stress on the epifoveolar tissue $[38,39]$. Other authors, however, demonstrated that it is possible to get favorable outcomes in myopic foveoschisis even without peeling ILM and, thus, with an easier and safer procedure [40]. A scleral imbrication combined with pars plana vitrectomy without ILM peeling has been described as an additional, effective method to treat myopic foveoschisis [41].

On the contrary, $\mathrm{MH}$ and $\mathrm{MH}$-retinal detachment (MHRD) necessitate the ILM peeling in order to release the tractional forces and may have greater benefit from surgical variants, such as the inverted ILM flap technique $[35,42]$. In the case of rhegmatogenous retinal detachment, ILM peeling seems to reduce the incidence of epiretinal membrane occurrence [43]; however, more studies are warranted to provide the indication to peel in this specific setting.

\section{Inverted ILM flap}

Many studies have demonstrated that myopic MHs have a worse closure rate than idiopathic ones [44]. This discrepancy has become even more evident with the introduction of the OCT, which has unequivocally shown that elongated eyes have worse anatomic outcomes following MH surgery [45]. Retinal shortening over an elongated sclera, often with posterior staphyloma, has been advocated as a causative factor [46].

In order to compensate for such retinal shortening, an "inverted ILM flap" technique has been attempted, to place the ILM in upside down position inside the MH [46]. In this way, the ILM acts as a scaffold for reactive gliosis and glial cell proliferation and, thus, anatomic MH closure occurs more easily [46]. Alternatively, ILM could act as a barrier preventing the fluid penetration from the vitreous into the macular hole preserving the function of the retinal pigment epithelium [47]. According to the original technique described by Michalewska and colleagues [46, 48], ILM is peeled circumferentially around the hole for about 2 disc diameters leaving the inner boundary attached to the MH edges. Then, the ILM is lifted, rolled and gently massaged inside the $\mathrm{MH}$ to cover it with the inverted ILM flap. At last, the fluid-air exchange is performed and the vitreous cavity is filled with air. In the postoperative period, patients are instructed to stay in a prone position up to a week following the surgery. Some variations of the technique have been proposed. If an ERM is present, it could be either peeled off or inverted with ILM $[46,49]$. Although some authors use all the ILM flap, it can be shortened using the cutter in order to increase its maneuverability and reduce the chance to have a flap displacement $[35,49]$. Alternatively, it is possible to peel the ILM with the exception of the area designated for the flap construction [50]. A mono-layered rather than a multi-layered ILM flap has been proposed with the aim to provide a more regular and physiological scaffold for gliosis [50, 51]. In order to prevent the traumatism to retinal nerve fibers, a modified $270^{\circ} \mathrm{C}$-shaped temporal ILM technique has been proposed [52]. Compared to the standard technique, the temporal variant was equally effective, but with a reduction in dissociated optic nerve fiber layer [47]. Additional advantages of temporal variant include the easier procedure, positioning of the flap in proper position with fewer efforts and manipulations, avoidance of ILM flap loss since ILM is not entirely removed. Choi et al. [53] proposed also an $180^{\circ}$ superior variant of ILM flap, which does not require the patient to maintain a prone position post-operatively.

After flap position, great attention must be paid to avoid turbulences that could displace the flap from its proper position. Spontaneous flap displacements or detachments are major concerns of the original technique, prolonging the surgery, requiring reposition maneuvers and leading to failure of surgery. On this regard, it has been suggested to perform a fluid-air exchange with low intraocular pressure and passive aspiration [35]. To secure the ILM flap during this step, it is also possible use Perfluoro-n-Octane [50], Viscoat [51] or autologous blood [54]. To further settle the flap, the vitreous cavity can be filled with gas $[35,49,55]$.

The anatomic success of inverted ILM flap for myopic $\mathrm{MH}$ without retinal detachment ranged from 94 to $100 \%$ $[35,46,55]$. A $100 \%$ closure rate has been reported even in eyes with axial length $\geq 30 \mathrm{~mm}$ or $\mathrm{MH}$ retinal detachment $[55,56]$. A comparative analysis disclosed that inverted ILM flap increase of 22 folds the chance to achieve anatomic success compared to complete ILM removal independently from the $\mathrm{MH}$ size [35].

The ILM inverted flap is a challenging maneuver and sometimes it cannot be performed due to ILM flap loss during the surgery or in the case of reoperation of eyes with $\mathrm{MH}$ that previously underwent complete ILM removal. In such setting, other alternative techniques have been proposed, such as the injection over the $\mathrm{MH}$ of autologous platelet-rich plasma [57], the autologous transplantation of ILM membrane [58], lens capsular flap [59] or even a flap of autologous peripheral neurosensory retina [60].

\section{Retinal detachment}

Highly myopic eyes have a tenfold risk increase of experiencing rhegmatogenous RD [61]. Almost 55\% of nontraumatic RD occurs in myopic eyes and, in addition, myopia poses at higher risk to develop RD following a blunt trauma [61, 62]. Besides peripheral retina lesions, 
$\mathrm{RD}$ may also arise from posterior paravascular tears and macular holes. Both $a b$ externo (i.e. scleral buckle) and $a b$ interno (i.e. pars plana vitrectomy) procedures may be applied, but they have a lower success rate in highly myopic eyes [63-65]. In the last decades, the use of scleral buckle declined in favor of pars plana vitrectomy [66].

Due to the increased axial length, thinning and fragility of highly myopic eyes, those eyes are at higher risk of surgical complications including muscle avulsion, vortex vein damage, hemorrhage, subretinal fluid retention, and globe perforation $[67,68]$. Since myopic patients are significantly younger than those with idiopathic RD, cataract development is a major concern in those patients [69]. Interestingly, cataract progression risk following vitrectomy is extremely low in patients $<50$ years old [70]. Scleral buckling carries the lowest risk of cataract onset and, thus, it should be considered as a primary option [71]. In case of pars plan vitrectomy, several precautions should be kept in mind in order to minimize cataract progression in these eyes and to avoid intra-operative cataract formation. Proper choice of instrumentation is the first step. Valved cannulas should be preferred to nonvalved ones and infusion volume should be kept low in order to create a controlled, gentle intraocular environment avoiding fluid turbulences. Although controversial, use of small gauge instruments may reduce the incidence of postoperative cataract [71, 72]. Peripheral vitrectomy with meticulous vitreous shaving is highly beneficial in eyes with $\mathrm{RD}$, especially in complicated cases, in order to prevent redetachment or proliferative vitreoretinopathy (PVR) [73-75]. In eyes with cataract, combined phacoemulsification and pars plana vitrectomy is a good option, since it allows a better shaving of vitreous base. In the case of a clear lens, however, several surgical expedients may be applied to avoid lens damage during the peripheral vitrectomy. By improving the visualization of the extreme peripheral retina and ora serrata, non-contact wide field viewing systems have been a technological step forward and are extremely precious in this setting [76]. Peripheral indentation may further aid the visualization of retinal periphery. Trocar cannula should be inserted at $4 \mathrm{~mm}$ posterior to the limbus since it allows a higher range of accessibility to the opposite retina without violating the anterior vitreous base [77]. Switching the hand of the vitreous cutter permits to reach the target without crossing the instruments behind the lens base. Curved instruments have been proposed to keep the distance from the posterior lens capsule during the peripheral vitrectomy [77-80]. Alternatively, standard small gauge instruments can be slightly bent to reach the peripheral retina without damaging the lens. Despite all these precautions, total removal of vitreous is arduous in phakic myopic eyes, since intraoperative complete posterior vitreous detachment may be even unachievable in some eyes due to strong vitreoretinal adhesion and posterior shifting of the vitreous base [81]. To further remove vitreous fibers, which may represent a scaffold for proliferation, the Diamond Dusted Membrane Scraper (Synergetics) or the FINESSE Flex loop (Alcon, Fort Worth, TX, USA) may be used to brush peripheral retina. Since myopic eyes have a more posterior vitreous base, a thinner sclera and incomplete posterior vitreous detachment, a scleral buckling in addition to pars plana vitrectomy has been proposed in order to provide a better adherence even after tamponade removal [81, 82]. However, this combined approach may lead to higher incidence of cataract [71] and no strong evidence demonstrated significant advantages over pars plana vitrectomy alone.

Another key point in these eyes concerns the use and the effect of internal tamponades. The irregular contours of the vitreous cavity for the presence of posterior staphyloma and peripheral ectasia may theoretically affect tamponade efficacy. It has been shown that gas tamponades perform better than silicon oil on retrospective studies [83, 84]. Mathematical models illustrated that silicone oil fails to tamponade irregular scleral contours [85]. In addition, silicon oil needs additional surgery for its removal and it may lead to several complications, including emulsion in anterior chamber, cataract, glaucoma, keratopathy, migration into the retina and/or optic nerve, and loss of myelinated optic nerve fibers [86]. For all these reasons, gas tamponades should be preferred to silicone oils in these eyes, except for complicated cases with PVR or for those arising from $\mathrm{MHs}$, which require a long-lasting tamponade [87]. Macular buckling may be performed in case of MHRD refractory to vitrectomy or even as a primary procedure [88-92]. Macular buckle changes the shape of the macula from concave to convex and, in this way, it alleviates antero-posterior and tangential tractions and causes an hyperopic shift [88-92]. Buckle sponges of different material and shape have been proposed [65, 93-95].

Evacuation of subretinal fluid is a further critical step, especially in the setting of MHRD. If a gas was used as a tamponade, subretinal fluid can be left in place since retinal pigment epithelium will pump out the fluid and gas will fill the new space. In case of MHRF, fluid could be drained directly from the hole itself using very small gauge instruments (i.e. $30 \mathrm{G}$ needle); however, this procedure could lead to hole enlargement or damage to its edges. Another option is to perform an inferior retinotomy to evacuate subretinal fluid and this step could be simplified if perfluorocarbon liquid is used, since it may displace peripherally the fluid.

An additional movie file shows a case of inveterate myopic retinal detachment complicated with PVR in a young, highly myopic patient (see Additional file 1). 


\section{Sclerotomy leakage}

One of the advantages of minimally invasive vitreoretinal surgery is the possibility to perform transconjunctival sutureless vitrectomy (TSV) thanks to self-healing small-diameter sclerotomies [96]. TSV is associated with shorter operative time, faster postoperative recovery, less postoperative inflammation, and less patient discomfort compared to traditional vitrectomy [96]. However, selfhealing sclerotomies not always remain tight, leading to spontaneous fluid loss and early postoperative hypotony; thus, precautionary intraoperative suture placement has been described in $1.3-11.2 \%$ of surgeries in general population [97-99]. In a retrospective case series by Woo et al. [99], myopia was an independent risk factor for sclerotomy leakage and early postoperative hypotony. One possible explanation is related to poor wound sealing due to myopic thinner sclera with deranged fibrillar architecture [100]. In addition, vitreous plugging could be less efficient in highly myopic eyes, because of extensive liquefaction [101]. Finally, the pressure on the sclera, exerted by the operators during the procedure in order to reach the posterior pole, could undermine wound sealing.

To avoid sclerotomy leakage, some precautions have been employed. Trocar insertion architecture is of primary importance: the intrascleral tunnel should be built in order to promote apposition of wound margins. Indeed, it has been demonstrated that biplanar obliqueperpendicular sclerotomies have lower incidence of leakage, conjunctival bleb formation, and postoperative hypotony, compared to straight cuts [102, 103]. Moreover, longer tunnels are structurally more secure than shorter ones [104]. Due to trigonometric laws, the narrow is the angle between the instruments and sclera, the longer is the incision wound; therefore, it is preferable to puncture the sclera with a narrow-angle [104]. Beyond angle of incision, also trocar blade bevel position has an impact on tunnel length, as bevel-down incision leads to longer tunnel than bevel-up cuts [105]. Finally, incision should be parallel to the limbus in order to avoid cutting of scleral fibers, which could impair the healing of the ocular surface $[106,107]$. Some authors $[108,109]$ suggested a tri-planar sclerotomy similar to cataract tunnel with a precut using a sharp instrument (e.g. stiletto blade) prior to trocar insertion with the theoretical advantages of having a longer tunnel, sharp margins, and increased valve effect.

Even with those precautions, sclerotomy leakage may eventually occur, due to myopic sclera altered architecture [99]. Although some of them can be managed with prolonged sclerotomy massage $[108,110]$, additional maneuvers are usually performed to prevent post-operative hypotony. A single transconjunctival and transscleral absorbable suture is a popular choice [111]. Although this manoeuver is relatively simple, cost-effective and requires no peritomy, it has some drawbacks (i.e. foreign body sensation and astigmatism) [112, 113]. In order to avoid such complications, other techniques have been proposed including releasable sutures $[114,115]$, use of tissue glue [116], polyethylene glycol-based hydrogel bandage [117, $118]$, and conjunctival cauterization [111, 119]. Although routine placement of sclerotomy sutures has been advocated in eye at high risk of leakage (e.g. highly myopic ones) [120], few pieces of evidences may be found in the current literature. In our practice, we usually place sutures in case of leakage after a careful examination of the sclerotomy and sclerotomy massage; in these eyes, however, the threshold to suture should be low.

Less than 10 years ago, Oshima et al. [121] introduced $27-\mathrm{G}$ vitrectomy with an incision size of $0.40 \mathrm{~mm}$. Since it does not require biplanar beveled trocar insertion and carries a very low risk of hypotony, 27-G vitrectomy offers extreme advantages in eyes with high myopia [122]. However, its employment may be limited in eyes with extremely high axial length and/or posterior staphyloma (see axial length paragraph) and a preoperative planning of should take in account all the above-mentioned variables.

\section{Methods of literature search}

A Pubmed engine search was carried out using the terms "myopia" paired with "vitrectomy" and "vitreoretinal surgery"; "posterior staphyloma"; "intraoperative optical coherence tomography"; "three-dimensional vitreoretinal surgery"; "chromovitrectomy"; "transconjunctival sutureless vitrectomy"; "internal limiting membrane"; "retinal detachment". All studies published in English up to July 2017 irrespective of their publication status were reviewed and relevant publications were included in this review.

\section{Conclusions}

To conclude, despite modern surgical devices, myopic eyes still represent a challenge for vitreoretinal surgeons. Many practical tips and tricks can make the surgical procedures simpler, significantly preventing sight-threatening intra- and post-operative complications. Future perspectives in this field include the shortening of the learning curve for each procedure, the introduction of novel technologies and new instruments in order to reach satisfying postoperative results.

\section{Additional file}

Additional file 1.27-G inveterate myopic retinal detachment. The additional movie file shows a pars plana vitrectomy in a young, phakic patient for inveterate retinal detachment complicated by proliferative vitreoretinopathy using 27 gauge instruments. 


\section{Abbreviations}

D: diopters; ERM: epiretinal membrane; G: gauge; ICG: indocyanine green; ILM: inner limiting membrane; iOCT: intraoperative optical coherence tomography; MH: macular hole; MHRD: macular hole-retinal detachment; PVR: proliferative vitreoretinopathy; RD: retinal detachment; TSV: transconjunctival sutureless vitrectomy; 3-D: three dimensional.

\section{Authors' contributions}

$M C, A R$, and FB participated in study design. AR and MVC carried out the literature search. MC and AR drafted the manuscript. MVC, GQ, and FB critically reviewed and revised the manuscript. All authors read and approved the final manuscript.

\section{Author details}

1 Ophthalmology Unit, Azienda Ospedaliera di Desio e Vimercate, Desio, Italy ${ }^{2}$ Department of Ophthalmology, University Vita-Salute, IRCCS Ospedale San Raffaele, Via Olgettina 60, 20132 Milan, Italy.

\section{Acknowledgements}

None.

\section{Competing interests}

The authors declare that they have no competing interests. The authors have no proprietary interest in the materials used in this study. Michele Coppola, Alessandro Rabiolo, Maria Vittoria Cicinelli: No disclosure. Giuseppe Querques consultant for: Alimera Sciences (Alpharetta, Georgia, USA), Allergan Inc (Irvine, California, USA), Bayer Schering-Pharma (Berlin, Germany), Heidelberg (Germany), Novartis (Basel, Switzerland), Sandoz (Berlin, Germany), Zeiss (Dublin, USA). Francesco Bandello has the following disclosures: ALLERGAN (S), ALIMERA (S), BAYER (S), FARMILA-THEA (S), SCHERING PHARMA (S), SANOFI-AVENTIS (S), NOVAGALI (S), PHARMA (S), HOFFMANN-LA ROCHE (S), GENENTECH (S), NOVARTIS (S).

\section{Availability of data and materials}

Material submitted for publication has not been previously reported and is not under consideration for publication elsewhere.

\section{Consent for publication}

All authors read and approved the final manuscript.

\section{Ethics approval and consent to participate}

Not applicable.

\section{Funding}

None.

\section{Publisher's Note}

Springer Nature remains neutral with regard to jurisdictional claims in published maps and institutional affiliations.

Received: 5 June 2017 Accepted: 16 August 2017

Published online: 02 October 2017

\section{References}

1. Battaglia Parodi M, Rabiolo A. Pathologic myopia. In: Schmidt-Erfurth U, Kohnen T, editors. Encyclopedia of ophthalmology. Berlin, Heidelberg: Springer; 2018.

2. Wong YL, Saw SM. Epidemiology of pathologic Myopia in Asia and Worldwide. Asia Pac J Ophthalmol (Phila). 2016:5:394-402. doi:10.1097/ APO.0000000000000234.

3. Morgan IG, He M, Rose KA. EPIDEMIC OF PATHOLOGIC MYOPIA: what can laboratory studies and epidemiology tell us? Retina. 2017;37:989_ 97. doi:10.1097/IAE.0000000000001272.

4. Garcia-Arumi J, Boixadera A, Martinez-Castillo V, Zapata M, Macià C. Surgery for myopic macular hole without retinal detachment. Eur Ophthalmic Rev. 2012;6:204-7.
5. Singh A, Fawzi AA, Stewart JM. Limitation of 25-gauge vitrectomy instrumentation in highly myopic eyes. Ophthalmic Surg Lasers Imaging. 2007;38:437-8.

6. Lytvynchuk LM, Sergiienko A, Richard G. Modified curved aspiration cannulas and end-gripping forceps for 25-gauge vitrectomy on highly myopic eyes. Retina. 2015;35:2660-3. doi:10.1097/ IAE.0000000000000883.

7. Gao X, Ikuno Y, Nishida K. Long-shaft forceps for membrane peeling in highly myopic eyes. Retina. 2013;33:1475-6. doi:10.1097/ IAE.0b013e318297f85b.

8. Oie Y, Emi K, Takaoka G, Ikeda T. Effect of indocyanine green staining in peeling of internal limiting membrane for retinal detachment resulting from macular hole in myopic eyes. Ophthalmology. 2007;114:303-6. doi:10.1016/j.ophtha.2006.07.052.

9. Sandali O, El Sanharawi M, Basli E, Lecuen N, Bonnel S, Borderie V, Laroche L, Monin C. Paracentral retinal holes occurring after macular surgery: incidence, clinical features, and evolution. Graefes Arch Clin Exp Ophthalmol. 2012;250:1137-42. doi:10.1007/s00417-012-1935-6.

10. Kuhn F, Mester V, Berta A. The Tano Diamond Dusted Membrane Scraper: indications and contraindications. Acta Ophthalmol Scand. 1998;76:754-5.

11. Lewis JM, Park I, Ohji M, Saito Y, Tano Y. Diamond-dusted silicone cannula for epiretinal membrane separation during vitreous surgery. Am J Ophthalmol. 1997;124:552-4.

12. Uchida A, Srivastava SK, Ehlers JP. Analysis of retinal architectural changes using intraoperative OCT following surgical manipulations with membrane flex loop in the DISCOVER study. Invest Ophthalmol Vis Sci. 2017;58:3440-4. doi:10.1167/iovs.17-21584.

13. Ehlers JP, Han J, Petkovsek D, Kaiser PK, Singh RP, Srivastava SK. Membrane peeling-induced retinal alterations on intraoperative OCT in vitreomacular interface disorders from the PIONEER study. Invest Ophthalmol Vis Sci. 2015;56:7324-30. doi:10.1167/iovs.15-17526.

14. Abdelkader $\mathrm{E}$, Lois N. Internal limiting membrane peeling in vitreoretinal surgery. Surv Ophthalmol. 2008;53:368-96. doi:10.1016/j. survophthal.2008.04.006.

15. Al-Halafi AM. Chromovitrectomy: update. Saudi J Ophthalmol. 2013;27:271-6. doi:10.1016/j.sjopt.2013.10.004.

16. Wollensak G. Biomechanical changes of the internal limiting membrane after indocyanine green staining. Dev Ophthalmol. 2008;42:82-90. doi:10.1159/000138975.

17. Philippakis E, Couturier A, Gaucher D, Gualino V, Massin P, Gaudric A, Tadayoni R. Posterior vitreous detachment in highly myopic eyes undergoing vitrectomy. Retina. 2016;36:1070-5. doi:10.1097/ IAE.0000000000000857.

18. Sakaguchi H, Ikuno Y, Choi JS, Ohji M, Tano T. Multiple components of epiretinal tissues detected by triamcinolone and indocyanine green in macular hole and retinal detachment as a result of high myopia. Am J Ophthalmol. 2004;138:1079-81. doi:10.1016/j.ajo.2004.06.078.

19. Ikuno Y. Current concepts and cutting-edge techniques in myopic macular surgeries. Taiwan J Ophthalmol. 2014;4:147-51. doi:10.1016/j. tjo.2014.03.006

20. Gomez-Resa M, Bures-Jelstrup A, Mateo C. Myopic traction maculopathy. Dev Ophthalmol. 2014:54:204-12. doi:10.1159/000360468.

21. Maia M, Haller JA, Pieramici DJ, Margalit E, de Juan E Jr., Farah ME, Lakhanpal RR, Au Eong KG, Guven D, Humayun MS. Retinal pigment epithelial abnormalities after internal limiting membrane peeling guided by indocyanine green staining. Retina. 2004;24:157-60.

22. Cacciatori M, Azzolini M, Sborgia M, Coppola M, De Molfetta V. Sodium hyaluronate $2.3 \%$ prevents contact between indocyanine green and retinal pigment epithelium during vitrectomy for highly myopic macular hole retinal detachment. Retina. 2004;24:160-1.

23. Facino M, Mochi B, Lai S, Terrile R. A simple way to prevent indocyanine green from entering the subretinal space during vitrectomy for retinal detachment due to myopic macular hole. Eur J Ophthalmol. 2004;14:269-71.

24. Rizzo S, Belting C, Genovesi-Ebert F, Vento A, Cresti F. Modified technique for safer indocyanine-green-assisted peeling of the internal limiting membrane during vitrectomy for macular hole repair. Graefes Arch Clin Exp Ophthalmol. 2006;244:1615-9. doi:10.1007/s00417-006-0316-4. 
25. Coppola M, La Spina C, Querques G, Bandello F. New dye injection technique by means of the "Drip Dropper" device. Retina. 2016;36:849. doi:10.1097/IAE.0000000000001016.

26. Toygar O, Berrocal MH, Charles M, Riemann CD. Next-generation dual-bore cannula for injection of vital dyes and heavy liquids during pars plana vitrectomy. Retina. 2016;36:582-7. doi:10.1097/ IAE.0000000000000747.

27. Chow DR. The evolution of endoillumination. Dev Ophthalmol. 2014;54:77-86. doi:10.1159/000360452.

28. Henrich PB, Valmaggia C, Lang C, Cattin PC. The price for reduced light toxicity: do endoilluminator spectral filters decrease color contrast during Brilliant Blue G-assisted chromovitrectomy? Graefes Arch Clin Exp Ophthalmol. 2014;252:367-74. doi:10.1007/s00417-013-2461-x.

29. Khan M, Ehlers JP. Clinical utility of intraoperative optical coherence tomography. Curr Opin Ophthalmol. 2016;27:201-9. doi:10.1097/ ICU.0000000000000258.

30. Eckardt C, Paulo EB. Heads-up surgery for vitreoretinal procedures: an experimental and clinical study. Retina. 2016;36:137-47. doi:10.1097/ IAE.0000000000000689.

31. Modi A, Giridhar A, Gopalakrishnan M. Comparative analysis of outcomes with variable diameter internal limiting membrane peeling in surgery for idiopathic macular hole repair. Retina. 2017;37:265-73. doi:10.1097/IAE.0000000000001123.

32. Steel DHW, Chen Y, Latimer J, White K, Avery PJ. Does internal limiting membrane peeling size matter? J VitreoRetin Dis. 2017;1:27-33.

33. Bando H, Ikuno Y, Choi JS, Tano Y, Yamanaka I, Ishibashi T. Ultrastructure of internal limiting membrane in myopic foveoschisis. Am J Ophthalmol. 2005;139:197-9. doi:10.1016/j.ajo.2004.07.027.

34. Iezzi R, Kapoor KG. No face-down positioning and broad internal limiting membrane peeling in the surgical repair of idiopathic macular holes. Ophthalmology. 2013;120:1998-2003. doi:10.1016/j. ophtha.2013.06.001.

35. Mete M, Alfano A, Guerriero M, Prigione G, Sartore M, Polito A, Pertile G. Inverted internal limiting membrane flap technique versus complete internal limiting membrane removal in Myopic macular hole surgery: a comparative study. Retina. 2017; doi:10.1097/IAE.0000000000001446.

36. Zhang Z, Wei $Y$, Jiang $X$, Zhang S. Pars plana vitrectomy and wide internal limiting membrane peeling with perfluoropropane tamponade for highly myopic foveoschisis-associated macular hole. Retina. 2017:37:274-82. doi:10.1097/IAE.0000000000001146.

37. Panozzo G, Mercanti A. Optical coherence tomography findings in myopic traction maculopathy. Arch Ophthalmol. 2004;122:1455-60. doi:10.1001/archopht.122.10.1455

38. HoTC, Chen MS, Huang JS, Shih YF, Ho H, Huang YH. Foveola nonpeeling technique in internal limiting membrane peeling of myopic foveoschisis surgery. Retina. 2012;32:631-4. doi:10.1097/ IAE.0B013E31824D0A4B.

39. Shimada N, Sugamoto Y, Ogawa M, Takase H, Ohno-Matsui K. Foveasparing internal limiting membrane peeling for myopic traction maculopathy. Am J Ophthalmol. 2012;154:693-701. doi:10.1016/j. ajo.2012.04.013

40. Qi Y, Duan AL, Meng X, Wang N. Vitrectomy without inner limiting membrane peeling for macular retinoschisis in highly myopic eyes. Retina. 2016;36:953-6. doi:10.1097/IAE.0000000000000826.

41. Baba T, Tanaka S, Nizawa T, Oshitari T, Yamamoto S. Scleral imbrication combined with pars plana vitrectomy without internal limiting membrane peeling for myopic schisis. Retina. 2016;36:1927-34. doi:10.1097/ IAE.0000000000001023.

42. Gao X, Guo J, Meng X, Wang J, Peng X, Ikuno Y. A meta-analysis of vitrectomy with or without internal limiting membrane peeling for macular hole retinal detachment in the highly myopic eyes. BMC Ophthalmol. 2016;16:87. doi:10.1186/s12886-016-0266-5.

43. Forlini M, Date P, Ferrari LM, Lorusso M, Lecce G, Verdina T, Neri G, Benatti C, Rossini P, Bratu A, D’Eliseo D, Ferrari TM, Cavallini GM. Comparative analysis of retinal reattachment surgery with or without internal limiting membrane peeling to prevent postoperative macular pucker. Retina. 2017;. doi:10.1097/IAE.0000000000001775.

44. Sulkes DJ, Smiddy WE, Flynn HW, Feuer W. Outcomes of macular hole surgery in severely myopic eyes: a case-control study. Am J Ophthalmol. 2000;130:335-9.
45. Suda K, Hangai M, Yoshimura N. Axial length and outcomes of macular hole surgery assessed by spectral-domain optical coherence tomography. Am J Ophthalmol. 2011;151(118-127):e111. doi:10.1016/j. ajo.2010.07.007.

46. Michalewska Z, Michalewski J, Dulczewska-Cichecka K, Nawrocki $J$. Inverted internal limiting membrane flap technique for surgical repair of myopic macular holes. Retina. 2014;34:664-9. doi:10.1097/ IAE.0000000000000042

47. Michalewska Z, Michalewski J, Dulczewska-Cichecka K, Adelman RA, Nawrocki J. Temporal inverted internal limiting membrane flap technique versus classic inverted internal limiting membrane flap technique: a comparative study. Retina. 2015;35:1844-50. doi:10.1097/ |AE.0000000000000555.

48. Michalewska Z, Michalewski J, Adelman RA, Nawrocki J. Inverted internal limiting membrane flap technique for large macular holes. Ophthalmology. 2010;117:2018-25. doi:10.1016/j.ophtha.2010.02.011.

49. Kuriyama S, Hayashi H, Jingami Y, Kuramoto N, Akita J, Matsumoto $M$. Efficacy of inverted internal limiting membrane flap technique for the treatment of macular hole in high myopia. Am J Ophthalmol. 2013;156(125-131):e121. doi:10.1016/j.ajo.2013.02.014.

50. Shin MK, Park KH, Park SW, Byon IS, Lee JE. Perfluoro-n-octane-assisted single-layered inverted internal limiting membrane flap technique for macular hole surgery. Retina. 2014;34:1905-10. doi:10.1097/ IAE.0000000000000339.

51. Song Z, Li M, Liu J, Hu X, Hu Z, Chen D. Viscoat assisted inverted internal limiting membrane flap technique for large macular holes associated with high myopia. J Ophthalmol. 2016;2016:8283062. doi:10.1155/2016/8283062.

52. Ho TC, Ho A, Chen MS. Vitrectomy with a modified temporal inverted limiting membrane flap to reconstruct the foveolar architecture for macular hole retinal detachment in highly myopic eyes. Acta Ophthalmol. 2017; doi:10.1111/aos.13514.

53. Choi SR, Kang JW, Jeon JH, Shin JY, Cho BJ, Oh BL, Heo JW. The efficacy of superior inverted internal limiting membrane flap technique for the treatment of full-thickness macular hole. Retina. 2017; doi:10.1097/ IAE.0000000000001619.

54. Lai CC, Chen YP, Wang NK, Chuang LH, Liu L, Chen KJ, Hwang YS, Wu WC, Chen TL. Vitrectomy with internal limiting membrane repositioning and autologous blood for macular hole retinal detachment in highly myopic eyes. Ophthalmology. 2015;122:1889-98. doi:10.1016/j. ophtha.2015.05.040.

55. Olenik A, Rios J, Mateo C. Inverted internal limiting membrane flap technique for macular holes in high myopia with axial length $\geq 30 \mathrm{~mm}$. Retina. 2016:36:1688-93. doi:10.1097/IAE.0000000000001010.

56. Chen SN, Yang CM. Inverted internal limiting membrane insertion for macular hole-associated retinal detachment in high myopia. Am J Ophthalmol. 2016;162(99-106):e101. doi:10.1016/j.ajo.2015.11.013.

57. Figueroa MS, Govetto A, Arriba-Palomero P. Short-term results of platelet-rich plasma as adjuvant to 23-G vitrectomy in the treatment of high myopic macular holes. Eur J Ophthalmol. 2016;26:491-6. doi:10.5301/ ejo.5000729.

58. Morizane Y, Shiraga F, Kimura S, Hosokawa M, Shiode Y, Kawata T, Hosogi M, Shirakata Y, Okanouchi T. Autologous transplantation of the internal limiting membrane for refractory macular holes. Am J Ophthalmol. 2014;157(861-869):e861. doi:10.1016/j.ajo.2013.12.028.

59. Chen SN, Yang CM. Lens capsular flap transplantation in the management of refractory macular hole from multiple etiologies. Retina. 2016;36:163-70. doi:10.1097/IAE.0000000000000674.

60. Grewal DS, Mahmoud TH. Autologous neurosensory retinal free flap for closure of refractory myopic macular holes. JAMA Ophthalmol. 2016;134:229-30. doi:10.1001/jamaophthalmol.2015.5237.

61. The Eye Disease Case-Control Study Group. Risk factors for idiopathic rhegmatogenous retinal detachment. Am J Epidemiol. 1993;137:749-57.

62. Lee TH, Chen YH, Kuo HK, Chen YJ, Chen CH, Lee JJ, Wu PC. Retinal detachment associated with basketball-related eye trauma. Am J Ophthalmol. 2017;180:97-101. doi:10.1016/j.ajo.2017.05.025.

63. Heimann H, Zou X, Jandeck C, Kellner U, Bechrakis NE, Kreusel KM, Helbig H, Krause L, Schuler A, Bornfeld N, Foerster MH. Primary vitrectomy for rhegmatogenous retinal detachment: an analysis of 512 
cases. Graefes Arch Clin Exp Ophthalmol. 2006;244:69-78. doi:10.1007/ s00417-005-0026-3.

64. Rodriguez FJ, Lewis H, Kreiger AE, Yoshizumi MO, Sidikaro Y. Scleral buckling for rhegmatogenous retinal detachment associated with severe myopia. Am J Ophthalmol. 1991;111:595-600.

65. Mura M, lannetta D, Buschini E, de Smet MD. T-shaped macular buckling combined with $25 \mathrm{G}$ pars plana vitrectomy for macular hole, macular schisis, and macular detachment in highly myopic eyes. Br J Ophthalmol. 2016; doi:10.1136/bjophthalmol-2015-308124.

66. Jackson TL, Donachie PH, Sallam A, Sparrow JM, Johnston RL. United Kingdom National Ophthalmology Database study of vitreoretinal surgery: report 3, retinal detachment. Ophthalmology. 2014;121:643-8. doi:10.1016/j.ophtha.2013.07.015.

67. Cheng SF, Yang CH, Lee CH, Yang CM, Huang JS, Ho TC, Lin CP, Chen MS Anatomical and functional outcome of surgery of primary rhegmatogenous retinal detachment in high myopic eyes. Eye (Lond). 2008;22:706. doi:10.1038/sj.eye.6702527.

68. Glazer LC, Mieler WF, Devenyi RG, Burton TC. Complications of primary scleral buckling procedures in high myopia. Retina. 1990;10:170-2.

69. Chen SN, Lian le B, Wei YJ. Epidemiology and clinical characteristics of rhegmatogenous retinal detachment in Taiwan. $\mathrm{Br}\lrcorner$ Ophthalmol. 2016:100:1216-20. doi:10.1136/bjophthalmol-2015-307481.

70. Kataria AS, Thompson JT. Cataract formation and progression in patients less than 50 years of age after vitrectomy. Ophthalmol Retina. 2017;1:149-53. doi:10.1016/j.oret.2016.09.007.

71. Feng $\mathrm{H}$, Adelman RA. Cataract formation following vitreoretinal procedures. Clin Ophthalmol. 2014;8:1957-65. doi:10.2147/OPTH.S68661.

72. Rizzo S, Genovesi-Ebert F, Murri S, Belting C, Vento A, Cresti F, Manca ML. 25-Gauge, sutureless vitrectomy and standard 20-gauge pars plana vitrectomy in idiopathic epiretinal membrane surgery: a comparative pilot study. Graefes Arch Clin Exp Ophthalmol. 2006;244:472-9. doi:10.1007/ s00417-005-0173-6.

73. Chaturvedi V, Basham RP, Rezaei KA. Scleral depressed vitreous shaving, 360 laser, and perfluoropropane (C3 F8) for retinal detachment. Indian J Ophthalmol. 2014;62:804-8. doi:10.4103/0301-4738.138621.

74. Martinez-Castillo V, Zapata MA, Boixadera A, Fonollosa A, Garcia-Arumi J. Pars plana vitrectomy, laser retinopexy, and aqueous tamponade for pseudophakic rhegmatogenous retinal detachment. Ophthalmology. 2007;114:297-302. doi:10.1016/j.ophtha.2006.07.037.

75. Teke MY, Balikoglu-Yilmaz M, Yuksekkaya P, Citirik M, Elgin U, Kose T, Ozturk F. Surgical outcomes and incidence of retinal redetachment in cases with complicated retinal detachment after silicone oil removal: univariate and multiple risk factors analysis. Retina. 2014;34:1926-38. doi:10.1097/IAE.0000000000000204.

76. Landers MB, Peyman GA, Wessels IF, Whalen P, Morales V. A new, noncontact wide field viewing system for vitreous surgery. Am J Ophthalmol. 2003;136:199-201.

77. Chalam KV, Shah VA, Gupta SK, Tripathi RC. Evaluation and comparison of lens and peripheral retinal relationships with the use of endolaser probe and newly designed curved vitrectomy probe. Retina. 2003;23:815-9.

78. Chalam KV, Gupta SK, Agarwal S. Illuminated curved vitrectomy probe for vitreoretinal surgery. Ophthalmic Surg Lasers Imaging. 2007:38:525-6.

79. Chalam KV, Shah GY, Agarwal S, Gupta SK. Illuminated curved 25-gauge vitrectomy probe for removal of subsclerotomy vitreous in vitreoretinal surgery. Indian J Ophthalmol. 2008;56:331-4.

80. Chalam KV, Shah VA, Tripathi RC. A curved vitrectomy probe. Ophthalmic Surg Lasers Imaging. 2004;35:259-60.

81. Ripandelli G, Rossi T, Scarinci F, Stirpe M. Encircling scleral buckling with inferior indentation for recurrent retinal detachment in highly myopic eyes. Retina. 2015;35:416-22. doi:10.1097/IAE.0000000000000389.

82. Solaiman KA, Dabour SA. Supplemental scleral buckling for inferior retinal detachment in silicone oil-filled eyes. Retina. 2014;34:1076-82. doi:10.1097/IAE.0000000000000037.

83. Lim LS, Tsai A, Wong D, Wong E, Yeo I, Loh BK, Ang CL, Ong SG, Lee SY. Prognostic factor analysis of vitrectomy for retinal detachment associated with myopic macular holes. Ophthalmology. 2014;121:305-10. doi:10.1016/j.ophtha.2013.08.033.

84. Mancino R, Ciuffoletti E, Martucci A, Aiello F, Cedrone C, Cerulli L, Nucci C. Anatomical and functional results of macular hole retinal detachment surgery in patients with high myopia and posterior staphyloma treated with perfluoropropane gas or silicone oil. Retina. 2013;33:58692. doi:10.1097/|AE.0b013e3182670fd7.

85. Fawcett IM, Williams RL, Wong D. Contact angles of substances used for internal tamponade in retinal detachment surgery. Graefes Arch Clin Exp Ophthalmol. 1994;232:438-44.

86. Russo A, Morescalchi F, Donati S, Gambicorti E, Azzolini C, Costagliola C, Semeraro F. Heavy and standard silicone oil: intraocular inflammation. Int Ophthalmol. 2017;. doi:10.1007/s10792-017-0489-3.

87. Rizzo S, Barca F. Vitreous substitute and tamponade substances for microincision vitreoretinal surgery. Dev Ophthalmol. 2014;54:92-101. doi:10.1159/000360454

88. Chen YP, Chen TL, Yang KR, Lee WH, Kuo YH, Chao AN, Wu WC, Chen $\mathrm{KJ}$, Lai CC. Treatment of retinal detachment resulting from posterior staphyloma-associated macular hole in highly myopic eyes. Retina. 2006:26:25-31.

89. Ripandelli G, Coppe AM, Fedeli R, Parisi V, D'Amico DJ, Stirpe M. Evaluation of primary surgical procedures for retinal detachment with macular hole in highly myopic eyes: a comparison [corrected] of vitrectomy versus posterior episcleral buckling surgery. Ophthalmology. 2001;108:2258-64 (discussion 2265)

90. Theodossiadis GP, Theodossiadis PG. The macular buckling procedure in the treatment of retinal detachment in highly myopic eyes with macular hole and posterior staphyloma: mean follow-up of 15 years. Retina. 2005;25:285-9.

91. Siam AL, El Maamoun TA, Ali MH. Macular buckling for myopic macular hole retinal detachment: a new approach. Retina. 2012;32:748-53. doi:10.1097/IAE.0b013e3182252a75.

92. Alkabes M, Bures-Jelstrup A, Salinas C, Medeiros MD, Rios J, Corcostegui B, Mateo C. Macular buckling for previously untreated and recurrent retinal detachment due to high myopic macular hole: a 12-month comparative study. Graefes Arch Clin Exp Ophthalmol. 2014;252:57181. doi:10.1007/s00417-013-2497-y.

93. Parolini B, Frisina R, Pinackatt S, Gasparotti R, Gatti E, Baldi A, Penzani R, Lucente A, Semeraro F. Indications and results of a new L-shaped macular buckle to support a posterior staphyloma in high myopia. Retina. 2015;35:2469-82. doi:10.1097//AE.00000000000000613.

94. Stirpe M, Ripandelli G, Rossi T, Cacciamani A, Orciuolo M. A new adjustable macular buckle designed for highly myopic eyes. Retina. 2012;32:1424-7. doi:10.1097/IAE.0b013e3182550648.

95. Wu PC, Sheu JJ, Chen YH, Chen YJ, Chen CH, Lee JJ, Huang CL, Chen CT, Kuo HK. Gore-tex vascular graft for macular buckling in high myopia eyes. Retina. 2017;37:1263-9. doi:10.1097/IAE.0000000000001376.

96. Chen E. 25-Gauge transconjunctival sutureless vitrectomy. Curr Opin Ophthalmol. 2007:18:188-93. doi:10.1097/ICU.0b013e328133889a.

97. Fine HF, Iranmanesh R, Iturralde D, Spaide RF. Outcomes of 77 consecutive cases of 23-gauge transconjunctival vitrectomy surgery for posterior segment disease. Ophthalmology. 2007;114:1197-200. doi:10.1016/j.ophtha.2007.02.020.

98. Kim MJ, Park KH, Hwang JM, Yu HG, Yu YS, Chung H. The safety and efficacy of transconjunctival sutureless 23-gauge vitrectomy. Korean J Ophthalmol. 2007;21:201-7. doi:10.3341/kjo.2007.21.4.201.

99. Woo SJ, Park KH, Hwang JM, Kim JH, Yu YS, Chung H. Risk factors associated with sclerotomy leakage and postoperative hypotony after 23-gauge transconjunctival sutureless vitrectomy. Retina. 2009;29:45663. doi:10.1097/IAE.0b013e318195cb28.

100. Curtin BJ, Iwamoto T, Renaldo DP. Normal and staphylomatous sclera of high myopia. An electron microscopic study. Arch Ophthalmol. 1979;97:912-5.

101. Soubrane G, Coscas G, Kuhn D. Myopia. In: Guyer DR, Yannuzzi LA, Chang S, Shields JA, Green WR, editors. Retina-vitreous-macula. Philadelphia: WB Saunders Co; 1999. p. 189-205.

102. Gutfleisch M, Dietzel M, Heimes B, Spital G, Pauleikhoff D, Lommatzsch A. Ultrasound biomicroscopic findings of conventional and sutureless sclerotomy sites after 20-, 23-, and 25-G pars plana vitrectomy. Eye (Lond). 2010;24:1268-72. doi:10.1038/eye.2009.291.

103. Lopez-Guajardo L, Vleming-Pinilla E, Pareja-Esteban J, Teus-Guezala MA. Ultrasound biomicroscopy study of direct and oblique 25-gauge vitrectomy sclerotomies. Am J Ophthalmol. 2007;143:881-3. doi:10.1016/j. ajo.2006.12.036.

104. Chen D, Lian Y, Cui L, Lu F, Ke Z, Song Z. Sutureless vitrectomy incision architecture in the immediate postoperative period evaluated in vivo 
using optical coherence tomography. Ophthalmology. 2010;117:20039. doi:10.1016/j.ophtha.2010.01.053.

105. Choi KS, Kim HD, Lee SJ. Sclerotomy site leakage according to wound shape in 23-gauge microincisional vitrectomy surgery. Curr Eye Res. 2010;35:499-504. doi:10.3109/02713681003663917.

106. Rizzo S, Genovesi-Ebert F, Vento A, Miniaci S, Cresti F, Palla M. Modified incision in 25-gauge vitrectomy in the creation of a tunneled airtight sclerotomy: an ultrabiomicroscopic study. Graefes Arch Clin Exp Ophthalmol. 2007;245:1281-8. doi:10.1007/s00417-006-0533-X.

107. Unal M, Balikoglu M, Teke MY, Koklu G. Comparison of two scleral incision techniques in 23-gauge transconjunctival vitrectomy. Ophthalmic Surg Lasers Imaging Retina. 2013;44:572-6. doi:10.3928/23258160-20131022-01.

108. Parolini B, Prigione G, Romanelli F, Cereda MG, Sartore M, Pertile G. Postoperative complications and intraocular pressure in 943 consecutive cases of 23-gauge transconjunctival pars plana vitrectomy with 1-year follow-up. Retina. 2010;30:107-11. doi:10.1097/IAE.0b013e3181b21082.

109. Shimozono M, Oishi A, Kimakura H, Kimakura M, Kurimoto Y. Three-step incision for 23-gauge vitrectomy reduces postoperative hypotony compared with an oblique incision. Ophthalmic Surg Lasers Imaging. 2011:42:20-5. doi:10.3928/15428877-20101025-02.

110. Takashina H, Watanabe A, Mitooka K, Tsuneoka H. Factors influencing self-sealing of sclerotomy performed under gas tamponade in 23-gauge transconjunctival sutureless vitrectomy. Clin Ophthalmol. 2014;8:2085-9. doi:10.2147/OPTH.S67932.

111. Reibaldi M, Longo A, Reibaldi A, Avitabile T, Pulvirenti A, Lippolis G, Mininni F, La Tegola MG, Sborgia L, Recchimurzo N, Sborgia C, Boscia F. Diathermy of leaking sclerotomies after 23-gauge transconjunctival pars plana vitrectomy: a prospective study. Retina. 2013;33:939-45. doi:10.1097/IAE.0b013e3182725d65.

112. Kellner L, Wimpissinger B, Stolba U, Brannath W, Binder S. 25-gauge vs 20-gauge system for pars plana vitrectomy: a prospective randomised clinical trial. Br J Ophthalmol. 2007;91:945-8. doi:10.1136/ bjo.2006.106799.
113. Yanyali A, Celik E, Horozoglu F, Nohutcu AF. Corneal topographic changes after transconjunctival (25-gauge) sutureless vitrectomy. Am J Ophthalmol. 2005;140:939-41. doi:10.1016/j.ajo.2005.05.042.

114. Lee BR, Song Y. Releasable suture technique for the prevention of incompetent wound closure in transconjunctival vitrectomy. Retina. 2008;28:1163-5. doi:10.1097/IAE.0b013e3181840b80.

115. Song Y, Shin YW, Lee BR. Adjunctive use of a novel releasable suture technique in transconjunctival vitrectomy. Retina. 2011;31:243-9. doi:10.1097/IAE.0b013e3181e586ce.

116. Panda A, Kumar S, Kumar A, Bansal R, Bhartiya S. Fibrin glue in ophthalmology. Indian J Ophthalmol. 2009:57:371-9. doi:10.4103/0301-4738.55079.

117. Hariprasad SM, Singh A. Polyethylene glycol hydrogel polymer sealant for vitrectomy surgery: an in vitro study of sutureless vitrectomy incision closure. Arch Ophthalmol. 2011;129:322-5. doi:10.1001/ archophthalmol.2011.13.

118. Singh A, Hosseini M, Hariprasad SM. Polyethylene glycol hydrogel polymer sealant for closure of sutureless sclerotomies: a histologic study. Am J Ophthalmol. 2010;150(346-351):e342. doi:10.1016/j. ajo.2010.04.002.

119. Boscia F, Besozzi G, Recchimurzo N, Sborgia L, Furino C. Cauterization for the prevention of leaking sclerotomies after 23-gauge transconjunctival pars plana vitrectomy: an easy way to obtain sclerotomy closure. Retina. 2011;31:988-90. doi:10.1097/IAE.0b013e31821361a5.

120. Ngo CT, Mokete B. A suture technique for leaking sclerotomies. Retina Today, July/August 2012, pp. 69-70.

121. Oshima Y, Wakabayashi T, Sato T, Ohji M, Tano Y. A 27-gauge instrument system for transconjunctival sutureless microincision vitrectomy surgery. Ophthalmology. 2010;117(93-102):e102. doi:10.1016/j. ophtha.2009.06.043.

122. Spandau U, Pavlidis M. Vitrectomy of myopic eyes. In: Spandau U, Pavlidis M, editors. 27-Gauge vitrectomy: minimal sclerotomies for maximal results. Switzerland: Springer; 2015. p. 269-70.

\section{Submit your next manuscript to BioMed Central and we will help you at every step:}

- We accept pre-submission inquiries

- Our selector tool helps you to find the most relevant journal

- We provide round the clock customer support

- Convenient online submission

- Thorough peer review

- Inclusion in PubMed and all major indexing services

- Maximum visibility for your research

Submit your manuscript at www.biomedcentral.com/submit
() Biomed Central 